\title{
Recycling of PVC pipes and fittings in Japan: proactive approach of industry to and its impacts on legal/technical frameworks
}

\author{
Shigetaka Seki ${ }^{1}$ Toshiaki Yoshioka ${ }^{2}$
}

Received: 25 February 2015/ Accepted: 17 July 2015/Published online: 7 August 2015

(c) The Author(s) 2015. This article is published with open access at Springerlink.com

\begin{abstract}
With growing concerns on increased waste emissions, depleting capacity for final disposal which triggered calls for new regulations on resource managements in the society, Japan PVC Pipes and Fittings Association (PPFA) started a voluntary recycling system proactively to retain flexibly in system operation and modification for efficiency and to avoid regulations which could be rigid. The system was successfully recognized by relevant laws as means to promote recycling. The voluntary action also contributed to improve the image of vinyl products. A key for success was to design a system which benefits both the PVC pipes and fitting industry and the existing companies engaged in waste treatment, processing, and recycling. To increase the amount of recycling, it was essentially important to develop a system in a way that quality post-use products were stably collected and the manufacturers of products made with recyclates could find customers. Coordinated measures needed to be taken including development of an efficient nationwide network for collection of waste products, preparation of quality guidelines for collection of wastes, information sharing
\end{abstract}

Vinyl Environmental Council, Japan, An industrial association of PVC and VCM manufacturers in Japan. http://www.vec.gr.jp/english/ index.html. Accessed 1 Aug 2013.

Shigetaka Seki

shigeseki@aol.com

Toshiaki Yoshioka

yoshioka@env.che.tohoku.ac.jp

1 The Vinyl Environmental Council (VEC), 1-4-1 Shinkawa, Chuo-ku, Tokyo, Japan

2 Graduate School of Environmental Studies, Tohoku University, 6-6-07 Aoba, Aramaki, Aoba-ku, Sendai, Miyagi 9808579, Japan with potential partners including local government bureaus in charge of installation and maintenance of water supplies or sewer, and developing national standards for products to ensure the quality of products.

Keywords Plastics recycling - Pipes and fittings - PVC

\section{The recycling system developed by the PVC Pipes and Fittings Association (PPFA) [1]}

An initiative was started in 1998 by the PVC Pipes and Fittings Association (PPFA) [1] to promote recycling of waste PVC pipes and fittings and to produce pipes and fittings made of the recyclates (Fig. 1). PPFA selected reliable partner companies with technical capacity and experiences of recycling. The partner companies buy waste pipes and fittings which meet the quality guidelines set by PPFA [2]. If the products do not meet the guidelines, the emitters of the wastes have to do either appropriate pretreatments to remove dirt and non-PVC materials by themselves or pay the fee for the pre-treatments. If they wish, the partner companies can ask PPFA to buy their products in forms as crushed, powdered recyclates [3]. Those who produce pipes made with $100 \%$ recyclates that meet PPFA standard (REP) may sell the pipes to PPFA. They receive incentive fees for cooperation from PPFA, part of which is fixed amount and the rest corresponding to the amounts of waste products they had received.

In areas where partner companies were remote, PPFA contracted with companies which functioned as intermediate receiving and storing points. In parallel, PPFA started to find and contract with reliable companies with expertise and experiences [4] which could receive post-use products to produce flakes and powders without financial incentives 
from PPFA. Those contracted companies were eligible to ask PPFA to buy their processed products. As the number of intermediate treatment companies grew to cover wider areas of the nation, PPFA reduced the number of the intermediate stockyards until total closure in 2014.

In January 2015, there were 14 contracted partner companies [5] and 66 contracted intermediate treatment companies [6]. In 2017, both will be merged to become a new form of contracted partners who share a fixed amount of incentive fees by PPFA. They will remain eligible to ask PPFA to buy their products of flakes and powders.

\section{The objectives and the backgrounds of the recycling of PVC pipes and fittings}

There were two objectives PPFA and PVC industry aimed at. One was to contribute to sustainable economy and society before regulatory framework was built up in detail and by thus to avoid rigid regulations. Another was to improve the image of the PVC products to protect the market. Such proactive industry actions with similar objectives can be found in other initiatives such as "Vinyl 2010" [7], "Vinyl Plus" [8] and the R\&D promotion program by Vinyl Environmental Council of Japan [9].

\section{For sustainable economy and society}

In the early ' $90 \mathrm{~s}$, the rapidly decreased capacity of landfill disposal became a big social issue calling for stringent actions for efficient use of resources and recycling-based society. The Act on the Promotion of Effective Utilization of Resources (PEUR) [10] was passed in 1991 to promote recycling of resources and to reduce the emissions of wastes. In 2001, the Basic Act on Establishing a Sound Material-Cycle Society [11] was enacted to promote recycling of materials and to reduce wastes. In parallel, the above-mentioned Act on PEUR was amended in 2001 [12] to promote not only recycling but also reduction of the use of resources and re-using goods and materials after use (so called "3R: Reduce, Reuse and Recycling”). In addition, the Waste Management and Public Cleansing Act [13] was amended to enforce appropriate disposal of wastes and the Construction Materials Recycling Law [14] was introduced to facilitate recycling of wastes generated in the construction sector. The PPFA was not passive in the development of new regulations to keep maximum flexibility with its proactive actions of recycling.

\section{Addressing the concerns over dioxins emissions}

Dioxins attracted public attentions by mid '90s. Media coverage on dioxins sharply increased in 1996 with messages that incinerations of vinyl products were a major source of emissions. Many local governments and companies announced their policies to avoid PVC products [15].

Vinyl industry appealed that the amount of dioxins emissions and the volume of PVC products incinerated were not related and the emissions could be dramatically reduced by controlling conditions of incineration with modern incinerators. Vinyl industry also tried to promote recycling in several product areas and the recycling of PVC pipes and fittings was a core [16].

\section{Market of PVC pipes and fittings: economic and social potential for recycling}

\section{Market of PVC pipes and fittings}

PVC pipes were first introduced to the market in Japan in 1951 [17]. The demand grew sharply from 4800 tons in 1955 to 55,000 tons in $1960,290,000$ tons in 1970 and 470,000 tons in 1990 . In early 2000, productions of pipes and fittings peaked above 500,000 tons, then gradually decreased as the number of newly built houses and buildings went down. In 2007, productions plunged due to the sharp decline in the number of new constructions as the result of the enforcement of building certifications triggered by the scandal of falsified quake-resistance data submitted by a structural designer. The demand stayed weak at around 350,000 tons due to the economic downturn precipitated by the Lehman Brothers bankruptcy. It went up slightly to 367,897 tons in 2013 as the economy gradually recovered then decreased to 312,651 tons in 2014 affected by the consumption tax increase of April 2014 (Fig. 2).

PVC pipes and fittings are used for drain and duct system in buildings and facilities, sewer, potable water supply, irrigation facilities, and protection of cables. In 2013, buildings and facilities accounted for $56 \%$ of demands, sewer $15 \%$, water supply $12 \%$, agriculture $4 \%$ and cable protection $2 \%$.

There are two types of PVC pipes which use recyclates. One is three-layer products with core layer made with recyclates and both inside and outside layers covered by virgin resin. There are two kinds of such products; one is those with foamed core and another is those with nonfoamed core. The other type of products is those made of $90 \%$ or more recyclates.

Three-layer pipes with foamed core are used for drain and duct pipes in the buildings. They are light in weight, good in thermal insulation performance, and stable in dimensions under thermal fluctuation. Three-layer pipes with non-foamed core layer are used as connecting 


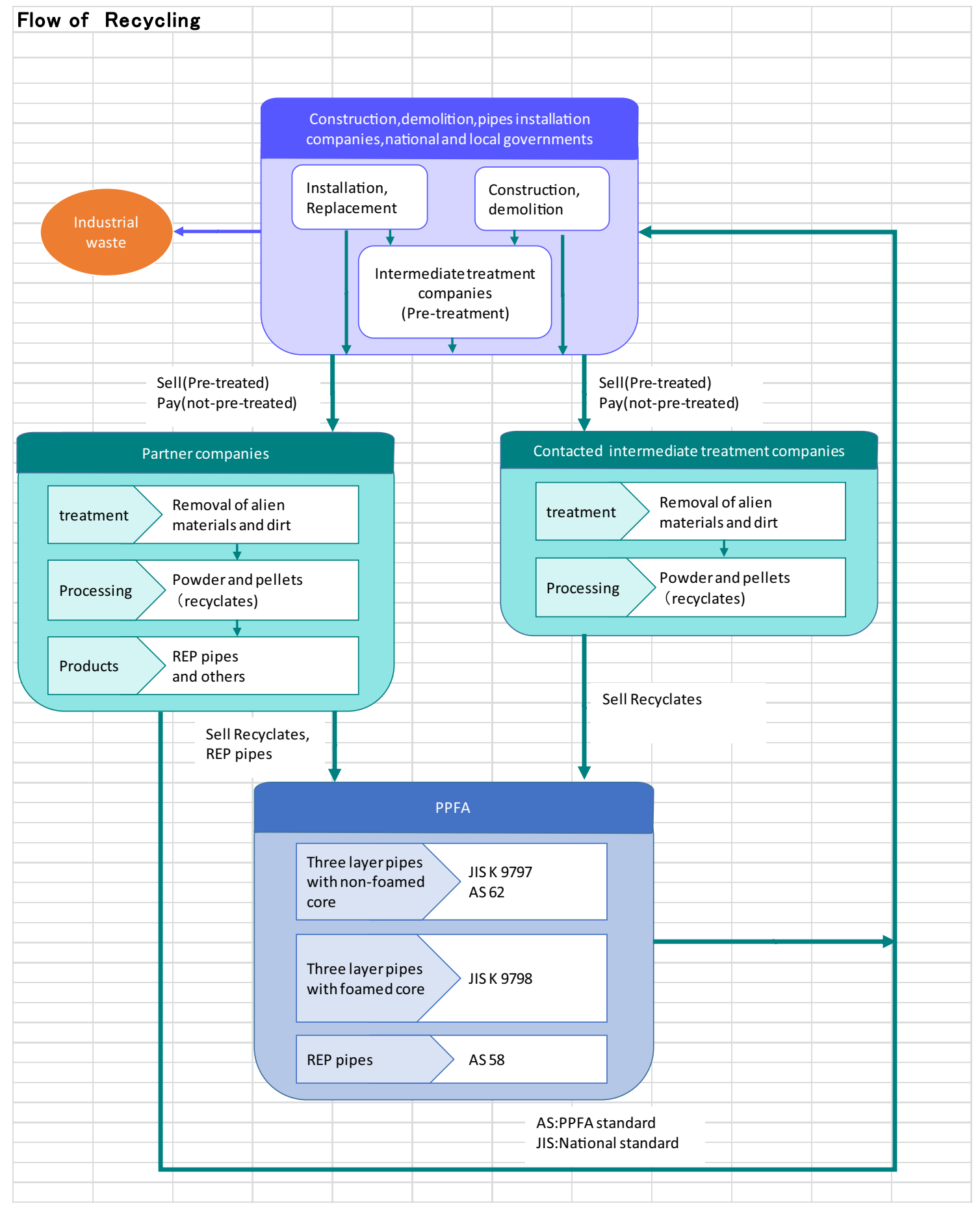

Fig. 1 PPFA's recycling system

mounting pipes for sewer and as sewer pipes for outdoor use. The pipes made of $90 \%$ or more recyclates which meets the PPFA standard are called REP pipes and used as outdoor drain pipes [18].

The volume of production of pipes containing recyclates is estimated some 2000 tons per year. Several thousand tons of single-layer pipes with recyclates not meeting the
PPFA standards are sold to niche market such as Do-ItYourself shops. The volume of production by independent recycling companies is estimated several thousands of tons. Very significant amount of recyclates is considered exported.

The volume of waste pipes and fittings collected in the PPFA recycling system increased from 4086 tons in 1998 
Fig. 2 Domestic shipments of PVC pipes and fittings (1000 tons)

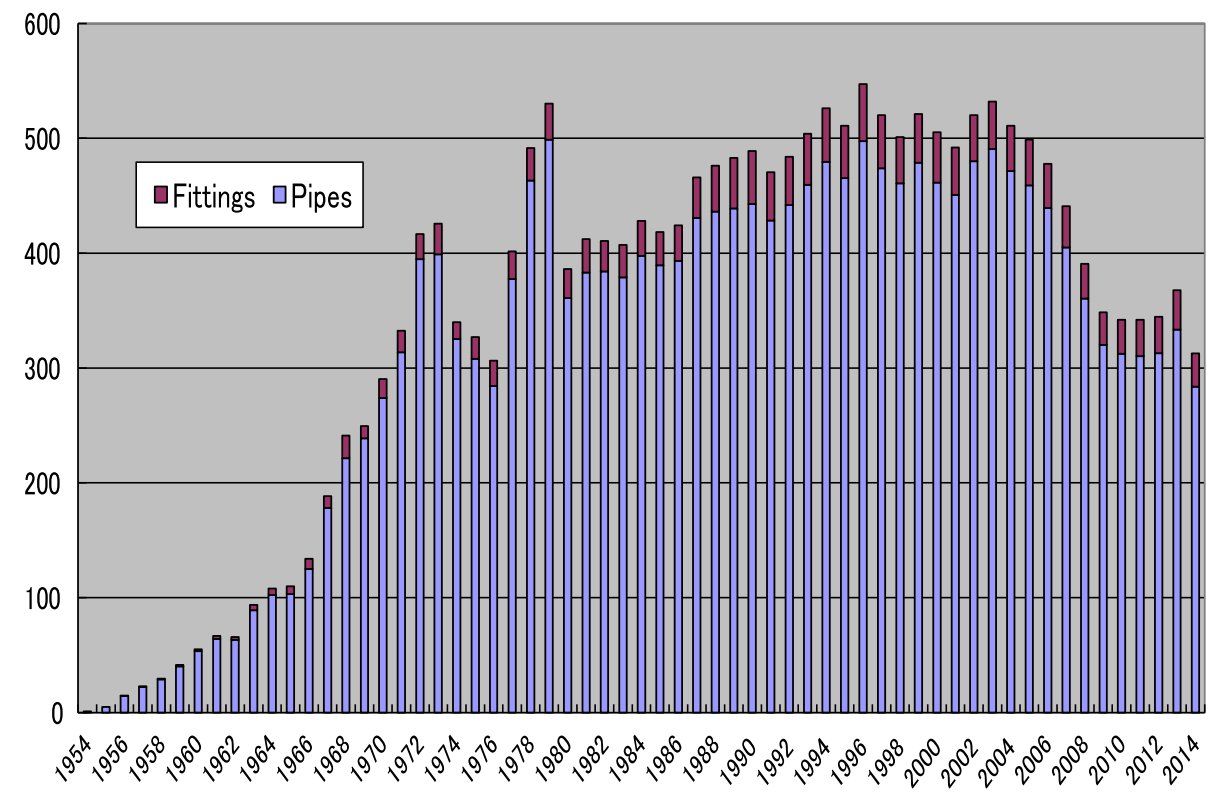

to 11,570 in 2006 reaching 18,466 tons in 2014 . The amount of recycling by independent business entities was estimated some 10,000 tons when the PPFA system started (Fig. 3).

\section{Technical and environmental advantage of recycling PVC pipes and fittings}

PVC pipes and fittings can last more than 50 years, virtually semi-permanently, without significant deterioration when installed underground [19]. By crushing them to flakes or powders, the wastes can become materials for new pipes and fittings if the quality of the collected products is high enough. The reborn products can be almost comparative to those made of virgin resins.
According to an industry data, the environmental load of the pipes made of recyclates were estimated significantly lower than that made of virgin resins, consuming only $1 / 4$ of energy and emitting $1 / 3$ of $\mathrm{CO}_{2}$ at production (Table 1).

\section{Social and economic environment for recycling PVC pipes and fittings}

Recycling of PVC pipes and fittings already existed in the '60s. Recycling business expanded in response to the price hike of resources after the First Oil Shock in 1973. Since the emissions of post-use products was limited due to long life of the products, primary sources of recyclates at that time were off-cuts at production and installation sites. As the manufacturers tried to recycle the off-cuts for
Fig. 3 Volume of recycling in the PPFA recycling system

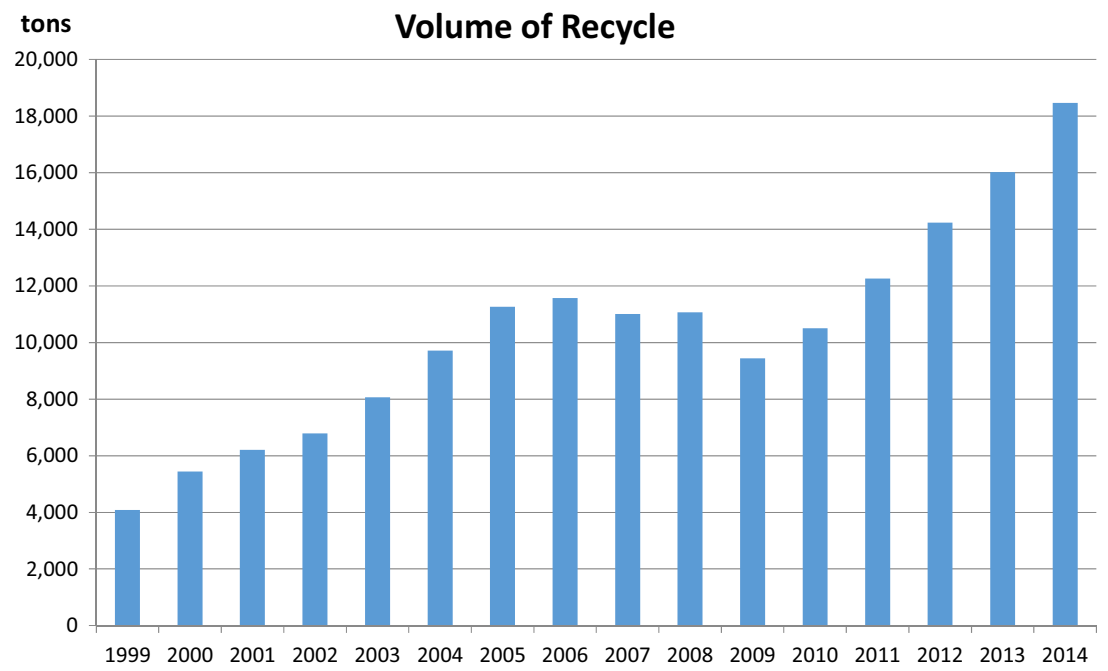


Table 1 Environmental load of PVC pipes made of virgin resin and recyclates [20]

\begin{tabular}{llcl}
\hline Load & Unit & Virgin resin & Recyclates \\
\hline Energy used & Mcal/kg & 10.86 & 2.50 \\
$\mathrm{CO}_{2}$ emitted & $\mathrm{kg} / \mathrm{kg}$ & 1.49 & 0.48 \\
NOx emitted & $\mathrm{g} / \mathrm{kg}$ & 2.15 & 0.50 \\
SOx emitted & $\mathrm{g} / \mathrm{kg}$ & 1.96 & 0.44 \\
\hline
\end{tabular}

Vinyl Environmental Council, PVC Fact Book 2005

themselves, collection of used products became important. Some intermediate treatment companies and manufacturers of pipes and fittings made of recyclates later became the partner companies or contracted intermediate treatment companies in the PPFA recycling system.

\section{History of designing the recycling system}

\section{History of studying and designing the system [21]}

As the Act on the Promotion of Effective Utilization of Resources being developed, industry started studies on possibilities of recycling in many areas. The vinyl industry in Japan established a council (in 1997 this council was named Japan PVC Environmental Council; JPEC [22]) for recycling in 1991 consisted of resin manufacturers and converters to study, do R\&D and transmit information, and to promote recycling. PPFA was a founding member.

In 1992, the council started studying recycling of three products, namely, bottles, packages for eggs, and the pipes and fittings [23]. PPFA chose Soka City in Shiga Prefecture as a place for field. PPFA cooperated with 17 companies engaged in installation of pipes and fittings to study the offcuts generated at the sites. In addition, PPFA arranged a truck to regularly visit the companies to collect the wastes. An aim of this collection was to find out the issues to be addressed in designing a collection system.

In the city, the amount of collection was about $2-3 \%$ of the total volume of products for new installation. Some $60 \%$ of the collected wastes were found good enough to mechanically recycle [23]. The studies conducted in other cities, namely Nara City, Hiratsuka City, Tochigi City, and Tokai City, showed similar results. PPFA studied also the existing recycling business. It found that there were several companies which produced pipes and fittings using recyclates. They were small businesses and could sell their products only in niche markets since their products did not meet JIS (Japan Industrial Standard) required for public procurement.

PPFA tried to improve recycling technologies. In 1993, it built a facility in one of its member companies to crush waste pipes to powders and to remove dirt and contaminants. PPFA confirmed that the quality of the pipes would not be affected in performance and appearance up to $15 \%$ content of recyclates. It examined the three-layer pipes with core layer made of recylates and to prove that the products were comparable in functional quality to pipes made of virgin resins with minor weakness that the inside of the pipes did not appear as good. However, the production cost was four times as high as that for pipes made of virgin resins.

In 1992, PPFA studied the situations overseas. There were a couple of cases in Netherlands [24] and in Germany [25]. In Netherlands, the PVC pipes and fitting industry made its own recycling system with their own facility for crushing the wastes to make materials for three-layer pipes and fittings. The government helped the recycling by establishing standards and disseminating information. In Germany, the collected wastes were mainly used to produce pipes for installation of cables.

\section{Designing and improvements of the recycling system}

To facilitate recycling, PPFA considered it better to cooperate with the existing companies rather than to develop an independent recycling system to compete with them. PPFA contracted with reliable companies, which had expertise and experiences and asked them to receive waste products, process them to be adequate as materials for pipes and fittings. PPFA would buy the recyclates if the partner companies wished. The partner companies would purchase waste products from the emitters if their quality met the criteria set by PPFA. They charge the emitters pretreatment fee for the products not meeting the criteria.

PPFA carried out a research to make a list of companies which collected waste products or produced products with recyclates so that PPFA could respond to inquiries from various entities including construction or demolition companies and local governments. PPFA worked closely with those companies and local cooperative associations engaged in installation of pipes.

PPFA contracted with 10 partner companies and officially announced the launch of its recycling system in December 1998 [26]. PPFA covered the costs of installing signboards to show that they were PPFA recycling system partners. It also supplied equipment to the partners as necessary. PPFA provided incentives to the partners with fixed amount fee and the fee based on the volume of recycling. The contracts were renewed every year unless major problems were found.

The partner companies could choose to sell the recyclates to PPFA, or sell them in the market for themselves. If they would want PPFA to take the recyclates they needed to obtain the acceptance of PPFA beforehand. Therefore, they needed to keep the recyclates for a month or more, but 
could expect that their recyclates would be taken by PPFA as long as the quality was good.

When the PPFA recycling system was launched, the volume of production of new PVC pipes and fittings was 500,000 tons per year. The wastes generated at the sites was estimated 15,000-20,000 tons per year and about $1 / 3$ (5000-6000 ton) of them was considered recycled into new products. The target set at the beginning was to double the volume of recycling and increase the recycling rate to $70 \%$ of the estimated emissions. PPFA aspired to achieve recycling rate of $100 \%$ in the future counting both feedstock and thermal recycling [26]. It prepared five hundred millions yen (around 4400,000 USD) for expenditures including installations of crushing machines, collection of waste pipes and fittings, incentive fees for partner companies, and administrative costs to operate the system. Vinyl Environmental Council, PVC resin makers' association, provided financial support to cover part of the cost.

To promote collection of waste products, PPFA contracted with companies which could function as intermediate receiving points. In 2002, PPFA introduced as many as 31 points which complemented the collection network of 17 partner companies with their 21 facilities. PPFA covered the costs of operation transportation from the points to the partner companies.

PPFA started contracting with intermediate treatment companies which could receive waste products and process them into mechanically recyclable materials in 2004 [27, 28]. The number of contracted intermediate treatment companies increased from three in 2004 to 69 by the beginning of 2015. Those contracted companies do not receive financial supports from PPFA, however, they expect to receive increased amount of wastes. They also see the contracts with PPFA as a proof of their good business practice to improve the social status. The contracted companies can sell the processed recyclates to PPFA if they wish, or sell by themselves.

PPFA reduced the number of the intermediate receiving points as the number of contracted intermediate treatment companies increased to cover wider areas of the country. There were 31 receiving points. It finally closed all intermediate receiving points by 2014 . PPFA negotiated with the contracted partner companies to terminate the incentive fee based on volume of recycling by 2014 (Fig. 4) and reduce the fixed amount incentive fee to zero by 2017, meaning that the status of the contracted partner companies and that of the contracted intermediate treatment companies will be the same. They will share a fixed amount of incentive money budgeted by PPFA for the recycling system. By these changes, operational cost of the recycling system will not fluctuate by volume of recycling, giving stability and predictability in the operation of the recycling system.

\section{Quality control of receiving waste products}

The emitters can sell wastes of good quality while they need to bear the costs of pre-treatment if the quality is not high enough. To avoid confusion and problems, PPFA shows the examples of good wastes that are purchasable and those which cannot be received in the system without pre-treatments (Fig. 5).
Fig. 4 Numbers of partner companies, receiving points, and contracted waste treatment companies

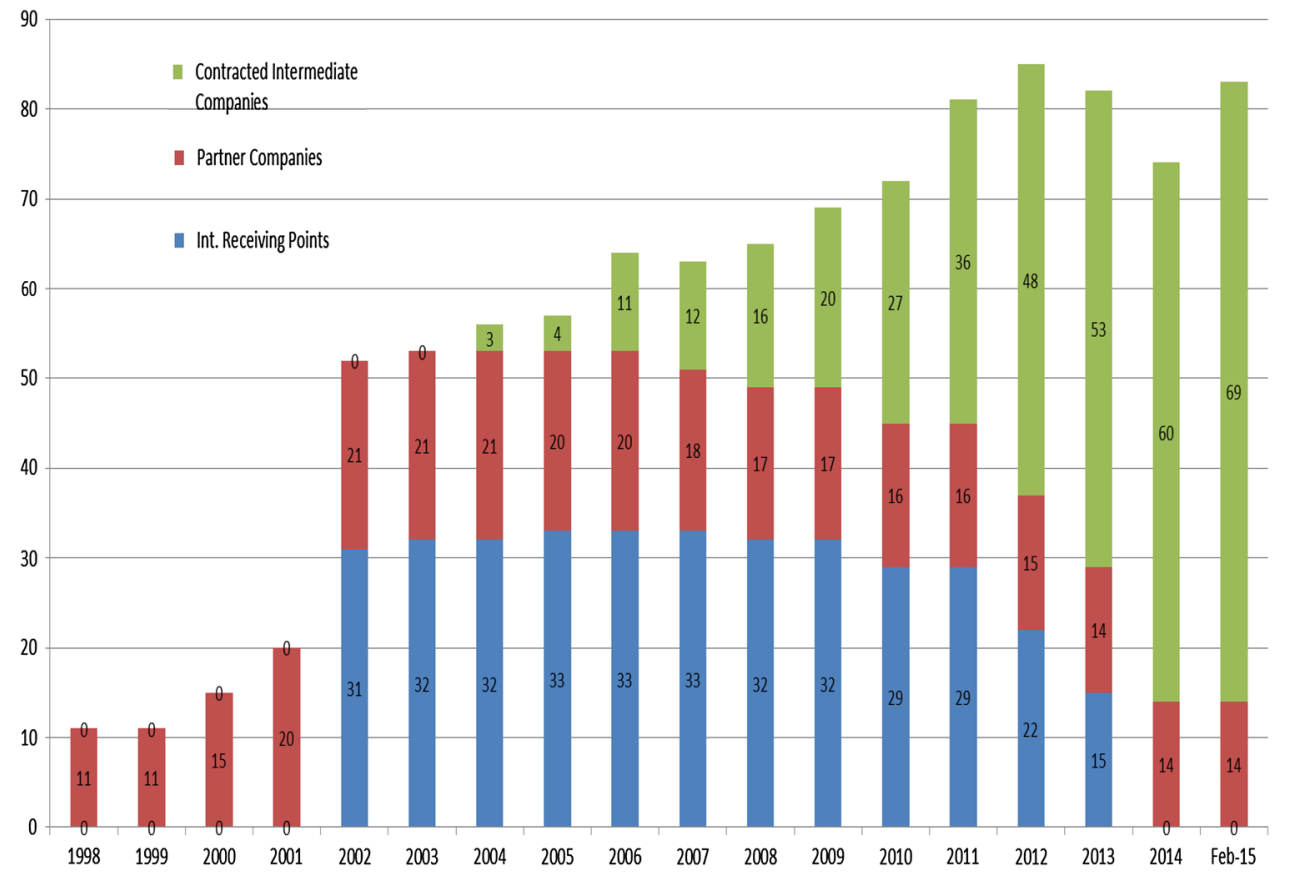


Fig. 5 Criteria for reception: those which need specific pretreatments to be purchased [29]

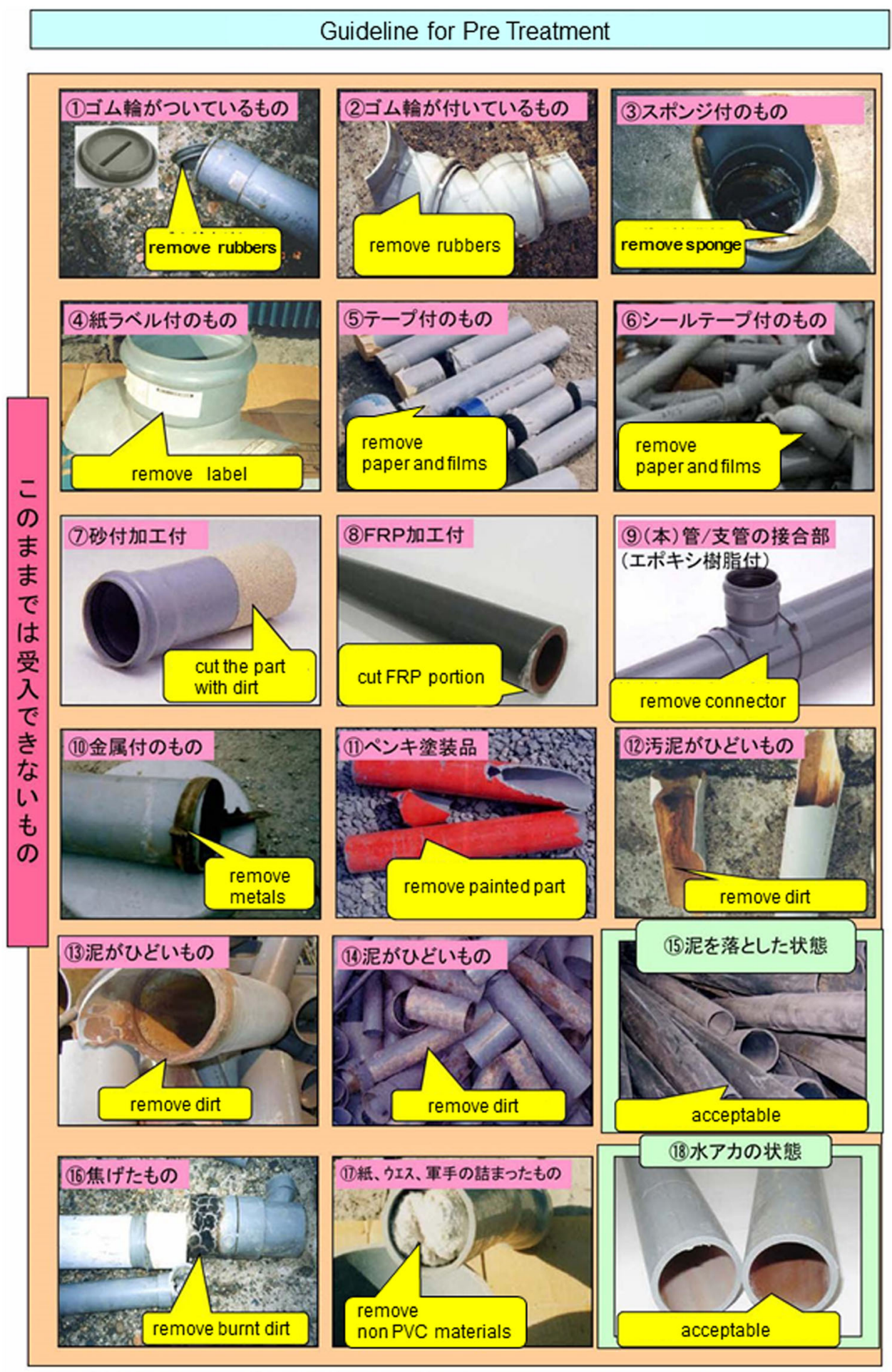

(注)切りくずや粉末状の硬質塩ビ品は、受入できません。

\section{Explore markets for products made of recyclates}

Public procurements for water supply and sewers are stable and important market for pipes and fittings. To be eligible for public procurement, it is necessary to ensure quality of products. PPFA was aware of the necessity of standards for products made with recyclates from the outset and prepared its first standard for pipes with $90 \%$ or more recyclates for drain (AS-58 [30]) as early as 1999. The standard, which is called REP, requires that the products should have quality 
performance comparable to the relevant national standards (JIS6741) for pipes made of virgin resin, although it limits applications to non-pressurized outdoor drain and requires minimum tensile strength $\left(39 \mathrm{MPa}\right.$ at $23^{\circ} \mathrm{C}$ ) lower than JIS (45 MPa) [31]. However, meeting JIS is not impossible with recyclates and there is a company producing JIS products. In 2000, PPFA developed two standards for three-layer pipes; AS-59 for pipes with foamed core (RFVU pipes) for drain water ways in buildings and AS-62 for pipes with non-foamed core (RS-VU pipes) for sewer system. The recyclates content of three-layer pipes is around $40 \%$ for those with foamed core and $60 \%$ for those with non-foamed core. PPFA negotiated with the Ministry of Construction so that the products which meet the PPFA standards be included in the lists of items for public procurement.

In 2003, National Green Procurement Guidelines included pipes and fittings with $30 \%$ or more recyclates as a specific procurement item. The premise was that there was system for collection of waste products for recycling, recognizing the recycling system of PPFA. In the following year, pipes made with recyclates were listed in the "Common Specifications for Publicly Utility Work" [32].

In 2006, two national standards-JIS K9797 for pipes with foamed core layer and JIS K9798 for pipes with nonfoamed core layer were added. These pipes became eligible for JIS Mark certification. In the same year, the National Green Procurement Guidelines added pipes and fittings made with recyclates for duct system. In 2011, the Procurement Guidelines were revised to be more practical and recyclates content requirements were set as $30 \%$ or more for three-layer pipes and $80 \%$ or more for single-layer pipes.

The company which is allowed to label JIS mark on its product will receive an inspection in several years to confirm appropriate quality management. Companies which produce products meeting relevant PPFA standards are allowed to put PPFA mark by receiving PPFA certification. PPFA inspects certified companies every year to ensure the quality of their products.

The Urban Renaissance Agency (URA), a public body to develop urban infrastructure leasing out homes and apartments, was quick to use pipes and fittings made with recyclates as early as 2001. It decided to deploy three-layer pipes for drain system in the building following its policies to promote environment friendly goods in 2003. At the URA's construction sites, three-layer pipes with foamed core layer were appreciated for their light weights and easiness to cut as compared to traditional pipes. The Metropolitan Tokyo Government decided to use pipes and fittings made with recyclates in its "Specifications for Homes and Apartments Owned by the Metropolitan Government" when it was revised in 2003. It also designated the pipes as an item for specific procurement in the Guidelines for Public Procurement by the Metropolitan Government made in 2004 [33, 34]. Ibaragi, Aichi, Wakayama, and Fukuoka Prefectures followed to use pipes made with recyclates. However, such green procurements only encourage the use of products with recyclates when the price is comparative. Pipes with recylates have disadvantages since they are more expensive than those with virgin resin.

\section{Estimation of the emissions of wastes}

PPFA launched a target of doubling the rate of mechanical recycling to $70 \%$ by 2000 , which was later raised to $80 \%$ by 2005 [26]. It is reasonably assumed that the rate was increased significantly as the volume of collection in the recycling system quadrupled. However, the achievement of the target was practically unverifiable as it was extremely difficult to know the amount of emissions every year.

First, the life of PVC pipes and fittings is very long or semi-permanent when installed underground [35]. The emissions of post-use products start decades after the installation, which makes it difficult to know the volume of emission at a particular year. In addition, the existing pipes and fittings are often kept undug when the houses or buildings are to be rebuilt. Therefore, the volume of emissions is considered much less than the volume installed.

There are four types of emissions for waste PVC pipes and fittings. The first type is the off-cuts generated at the sites of construction or installation and in the process of retailing. Such emissions occur relatively shortly after production and shipment of the products and estimated at around $1.5 \%$ of total shipment, or 4000-5000 tons per year.

The second type is the emissions at the sites of demolition. The volume can be estimated based on the public statistics on construction which shows the lost square measures of residential and non-residential buildings. PPFA estimates that such emissions amount to some 10,000 tons per year.

The third type of emissions is those from the facilities and equipment of factories. Assuming that facilities and equipment are rebuilt or replaced on average in 10 years, PPFA estimates that the emissions are at around 10,000 tons per year.

The last one is those from the replacement of water supply and sewer systems. Assuming that $80 \%$ of the existing pipes and fittings are undug, and the replacements peak on average 45 years after replacement, PPFA estimates the volume of such emissions some 10,000 tons a year. 
In total, emissions of the waste pipes and fittings were estimated 32,000-35,000 tons per year in the past 10 years. All four types of emissions are affected by business cycle and there are no ways to make a precise estimation for particular year. Given the fact that several thousand tons of waste products are recycled outside the PPFA recycling system, the total volume of recycling in the past years is estimated around 20,000 tons per year, meaning that the recycling rate was $60-70 \%$ in the past years, almost doubled since the PPFA recycling system had started [36].

Estimation of the emissions will be more difficult in the future due to several reasons. The emissions from the replacement of water supply and sewer system are expected to grow considering the fact the shipment of PVC pipes and fittings has sharply increased since 50 years ago. Thanks to the PPFA's recycling system, more of the pipes and fittings installed underground for water supply and sewer systems are considered to have been dug out for recycling. On the other hand, the cycle of replacements is likely to be prolonged due to the tightened budget constraints of the local governments. Demands for replacements of facilities and equipment in factories have been weak in the past decades due to economic stagnation and transfer of production capacity overseas. Therefore, PPFA decided not to use the target of recycling rate but to do every effort to increase the volume of recycling.

\section{Analysis}

\section{The objectives of the recycling system and the achievements}

The two primary objectives of launching the recycling system were to demonstrate to the society, orienting toward recycling, positive attitude of the industry and to avoid regulatory intervention by voluntary industry actions, and to address the concerns over dioxins.

The PPFA recycling system was developed in the process amending the Act on the Promotion of Effective Utilization of Resources of 1991 and was recognized in the revised law of 2001 [37]. Designated as Resource Saving Industry under the law, PVC pipes and fittings industry were requested to undertake five actions. First, it should promote the use of recyclates in collaboration with the construction industry, local and national governments to increase the share of products made of recyclates as much as possible. Second, it should deploy facilities and equipment for recycling as necessary. Third, it should advance technologies such as removing alien materials and to use more degraded post-use products. Fourth, it should make a plan for and report of its action every year. Fifth, it should endeavor to disseminate information for understanding of product users to facilitate recycling. These actions were what PPFA was already undertaking. Therefore, the law was seen to recognize and encourage the efforts of the industry, and not to introduce additional controls or burdens.

The guideline (2000) of the Construction Materials Recycling Law [38] recognizes and encourages the industry efforts by saying that PVC pipes and fittings industry has started its own effort of recycling, therefore, concerned parties need to cooperate with the system as much as possible. Being successful to avoid rigid regulations, PPFA has kept flexibility in operation and modification of the system.

With regard to the objective to address the dioxins issue, the Green Purchasing Network (GPN) Guidelines, which give guidance to green purchases of the governments, were revised in February 2014 to dispel an article which mandated the indication of the use of PVC materials for some ten product items due to the concern on dioxins generation [39]. The industry efforts to recycle PVC products were considered to have played an important role for the revision of GPN guidelines.

\section{Economy and practicality of the recycling system}

There are four reasons that PPFA was successful.

First, PPFA had closely studied the situation of available and potential technologies for recycling before it launched its recycling system, and designed a system to take advantage of the existing business entities. The partner companies could expect to receive more waste products stably, and appreciated that PPFA could buy their products. They also wished that the products made with recyclates would not compete with those with virgin resins in the market [40]. PPFA successfully designed the system to respond to these expectations.

Considering that lower grade pipes made with recyclates were sold to niche markets for Do-It-Yourself and others, PPFA aimed to produce high quality pipes with recyclates of comparative performance to virgin resin JIS pipes so that they could be publicly procured. With a prospect of increased amount of stable supply of the waste products, the recycle-business partners were willing to invest in the business. PPFA supported them to install additional facilities and equipment for recycling. Some intermediate treatment companies made investments for themselves.

Second, PPFA developed the collection network effectively, even with introduction of costly intermediate receiving points as a temporary measure since PPFA considered it necessary to widen the network to cover the country as soon as possible. In fact, the transportation cost of wastes from the intermediate receiving points to partner companies was as high as 50 yen (40 US cents) per kg [41, 
42], almost twice the cost for landfill. In addition, PPFA covered the operational costs of the stockyards. The number of the intermediate receiving points was gradually reduced to zero in 2004 as the number of contracted intermediate treatment companies grew to 60 . In reality, volume received at the receiving points to $300-600$ tons per year, or 3-5\% of the total amount of recycling in the PPFA system. However, the existence of intermediate receiving points is considered to have contributed to earn reliability and credibility.

Third, PPFA actively disseminated information to local governments, association of pipe installation companies, recycle businesses, and construction and demolition companies to develop connections among them. By this, more post-use products which were otherwise kept underground or sent to landfill were considered and brought into the PPFA recycling system. Indeed, many partner companies reported that the amount of receiving waste products increased after they had joined the PPFA system [43]. Misawa Home, a major home builder with its own network for collection and separation of waste construction materials took advantage of the PPFA system. The trucks which transport new construction materials to a construction site carry back wastes from the site to a PPFA partner to improve economic efficiency [44]. Sekisui House and Daiwa House, other major home builders, are doing similarly, carefully selecting PVC wastes at their construction sites to sell the wastes to an intermediate treatment company contracted with PPFA [45]. Takenaka Construction Company works together with a PPFA partner company (Nisshin Chemical Co.) to do thorough separation at the sites of construction before the waste products are sent to Takenaka's focal stock point for recycling. Transportation costs can be reduced by carrying back many kind of separated materials at once, so, PVC pipes and fittings which are emitted in small volume at each site can be economically collected [46].

Fourth, the industry fully recognized the need for assuring quality of the products made of recyclates and developed guidelines for acceptable wastes products and its own standards followed by JIS standards to ensure the quality of products with recyclates. By these standards, the pipes made with recyclates became qualified for government green procurements.

With these efforts, the cost of operating the recycling system was significantly reduced while the volumes of recycling sharply increased. PPFA allocated 1 million USD or more for the operation in addition to the initial investment for equipment and facilities which amounted at around 1.5 million USD in total. However, the operation cost has been more than halved recent years. The cost of recycling for PPFA was more than 20 US cents at the beginning, which was comparable to the cost for final disposal to landfill, is now several cents per kilogram of collected wastes. However, production of pipes made with recyclates to meet JIS or PPFA standards is more costly than that with virgin resin. These years, significant amounts of recyclates are purchased by export traders who consequently increase the price of waste products.

The Law on Promoting Green Purchasing [47] obligates the national government to procure the goods which meet the criteria set under the law. However, it only encourages local governments, which are more influential in infrastructure developments and maintenances to do so. They are not motivated to buy goods with recyclates at prices higher than those without recyclates. This is a major reason why the production of three-layer pipes is limited.

\section{Conclusion}

A voluntary industry initiative of recycling worked effectively, recognized by relevant laws, and successfully avoid rigid regulations. The PVC pipes and fittings industry could keep flexibilities in the operation and modification of its recycling system. Actions by the industry contributed much to improve the image of PVC products and to obtain social understanding. In light of the original objectives, the voluntary recycling was a major success.

PPFA developed its standards to ensure quality of the products which contributed to designation of the products by national and local governments. However, the production and shipment of such pipes are limited since the costs for production are high and very significant amounts of recyclates are considered exported. To expand the use of pipes made with recyclates domestically, it should be necessary to obligate local governments to purchase items listed under the green purchase law. Such obligation could be justifiable considering the contribution to save space for landfill and better environmental load.

Open Access This article is distributed under the terms of the Creative Commons Attribution 4.0 International License (http://creati vecommons.org/licenses/by/4.0/), which permits unrestricted use, distribution, and reproduction in any medium, provided you give appropriate credit to the original author(s) and the source, provide a link to the Creative Commons license, and indicate if changes were made.

\section{References}

1. An industry association founded in 1954. The members include ten PVC pipes and fittings manufacturers and four related industry associations. Recycling of PVC pipes has been a major activity of the association. http://www.ppfa.gr.jp/. Accessed 14 Feb 2015

2. PPFA guidelines for purchasable waste pipes and fittings http:// www.ppfa.gr.jp/recycle/purchase/standard.html. Accessed 14 Feb 2015 
3. Some partner companies and contracted intermediate treatment companies produces pellets as well. However, PPFA does not buy pellets as they are compounds with additives for specific applications

4. Eligibility of application for contracted intermediate treatment companies set by PPFA. http://www.ppfa.gr.jp/recycle/bosyu/

5. PPFA Partner Companies http://www.ppfa.gr.jp/recycle/purchase/ list.html. Accessed 14 Feb 2015

6. PPFA Contracted Intermediate Treatment Companies http:// www.ppfa.gr.jp/recycle/disposal/list.html. Accessed 14 Feb 2015

7. Buekens A, Sevenstar A (2010) Vinyl 2010-nearing the target date. J Mater Cycles Waste Manag 12:184-192

8. Sevenstar A (2012) Vinyl Plus, the new European PVC industry's voluntary programme toward sustainability. J Mater Cycles Waste Manag 14:281-285

9. Seki S, Osakada F, Yoshioka T (2014) Development in an industry-led R\&D program for recycling PVC products in Japan. J Mater Cycles Waste Manag 16:385-397

10. The Act on the Promotion of Effective Utilization of Resources, http://www.japaneselawtranslation.go.jp/law/detail/?id=80\&vm= $04 \&$ re $=01 \&$ new $=1$. Accessed 14 Feb 2015

11. The Basic Act on Establishing a Sound Material-Cycle Society, http://www.japaneselawtranslation.go.jp/law/detail/?id=2042\&vm= $04 \&$ re $=01 \&$ new $=1$. Accessed 14 Feb 2015

12. The Act on the Promotion of Effective Utilization of Resources http://www.meti.go.jp/policy/recycle/main/admin_info/law/02/ sigenyukoriyoho.html. Accessed 14 Feb 2015

13. The Waste Management and Public Cleansing Act http://law.egov.go.jp/htmldata/S45/S45HO137.html. Accessed 14 Feb 2015

14. The Construction Materials Recycling Law http://law.e-gov.go. jp/htmldata/H12/H12HO104.html. Accessed 14 Feb 2015

15. Commemorative of the fifty years of PPFA, $p$ 43, PPFA

16. "60 year history of PPFA, Part II" Japan Sewer News Paper, 1 Oct 2014

17. "An outline of development of poly vinyl chloride technology in Japan, including a description of historical material (2), 2002, Maki Miyamoto, National Museum of Nature Science, Japan, http://sts.kahaku.go.jp/diversity/document/system/pdf/007.pdf. Accessed 14 Feb 2015

18. Koichi Ishizaki (2011) "Situation of recycling of the post use PVC pipes and fittings, the projection of the emissions, and issues to be addressed", Construction Materials Recycling, 2011 Winter, vol 54, p 16

19. "PVC pipes can last more than 50 years", PPFA http://ppfa.gr.jp/ 02/index-a04.html (Accessed 14 Feb. 2015)

20. PVC Fact Book 2005, Vinyl Environmental Council (2005) "LCI data of mechanical recycling", pp 63 http://www.vec.gr.jp/lib/ pdf/factbook.pdf. Accessed 11 May 2015

21. "Commemorative Publication to Celebrate Sixty Years of PPFA", PPFA

22. Japan PVC Environmental Council, http://www.pvc.or.jp/index/ i_gaiyo.html. Accessed $14 \mathrm{Feb} 2015$

23. PVC News 1992/6, vol 1, JPEC, http://www.pvc.or.jp/news/01-3. html. Accessed 14 Feb 2015

24. "Final Report, Mechanical Recycling of PVC Wastes: Study for DG XI of the European Commission", January 2000, pp 65

25. PVC News, vol 26, 1998/9, JPEC, http://www.pvc.or.jp/news/ 26-1.html. Accessed 14 Feb 2015

26. PVC News vol 28, 1999/3, JPEC http://www.pvc.or.jp/news/ 28-3.html. Accessed $14 \mathrm{Feb} 2015$

27. The conditions include having permit to receive and treat wastes, ability to process PVC pipes and fittings and having business experience. http://www.ppfa.gr.jp/recycle/bosyu/. Accessed 14 Feb 2015
28. PVC News Vol. 48, 2014/3, JPEC http://pvc.or.jp/news/48-01. html (Accessed 14 Feb 2015)

29. PPFA guideline for wastes to be purchasable http://www.ppfa.gr. jp/recycle/pdf/ukeire-gaikan.pdf. Accessed 14 Feb 2015

30. REP Standard, PPFA, http://www.ppfa.gr.jp/02/index-c05.html. Accessed 14 Feb 2015

31. PVC News vol 29 1999/6, JPEC, http://www.pvc.or.jp/news/ 29-12.html. Accessed 14 Feb 2015

32. "The numbers of products qualified for green purchase and ecomark are increasing" http://www.vec.gr.jp/recycle/recycle5_4. html. Accessed 14 Feb. 2015

33. PVC News vol 49, 2004/6, JPEC, http://www.pvc.or.jp/news/ 49-02.html. Accessed 14 Feb 2015

34. PVC News vol 52, 2005/3, JPEC http://www.pvc.or.jp/news/ 52-01.html. Accessed 14 Feb 2015

35. "PVC Fact Book 2005", Vinyl Environmental Council, pp 35 http://www.vec.gr.jp/lib/pdf/factbook.pdf. Accessed 14 Feb 2015

36. The rate of recycling was estimated $65 \%$ in 2005. "Clean Japan News Letter, No. 21", March 2008, PP. 3, Centre for Promotion of Recycling, Japan Environmental Management Association for Industry http://www.cjc.or.jp/cjc/newsletter/indexletter21Jmain03. html. Accessed 14 Feb 2015

37. Article 15-17 of the law. Five groups of industry have become Designated Resource Saving Industry in the law, included PVC pipes and fittings manufacturing industry, paper manufacturing industry, glass container manufacturing industry, copy machines manufacturing industry and construction industry. http://www. cas.go.jp/jp/seisaku/hourei/data/peur_2.pdf. Accessed 14 Feb 2015

38. Basic Guideline of the Construction Materials Recycling Law 3-2-(1)-4. http://www.mlit.go.jp/sogoseisaku/const/kengyo/kihon housin/kihonhousin.htm. Accessed 14 Feb 2015

39. News on the Revision of GPN Guidelines: Repealing the Item to Obligate Notification of the Use of PVC, 2014/02 Green Purchasing Network, http://www.gpn.jp/archives/gpnnews/archive/ 2014/02/000682.php. Accessed 14 Feb 2015

40. PVC News vol 29, 1999/6, JPEC, http://www.pvc.or.jp/news/292.html. Accessed 14 Feb 2015

41. PPFA arranged a truck to collect 20 cases of wastes products which weighed around 2 tons. The average transportation cost by a truck was around 1,000 USD

42. According to a report (Industrial Wastes of Plastics; Their Emissions, Treatment and Disposal, 2014) by the Plastic Waste Management Institute of Japan (PWMI), disposal costs for flexible and rigid PVC products in the past four years were 27-41 yen $/ \mathrm{kg}$ and $26-42 \mathrm{yen} / \mathrm{kg}$. The disposal costs were not particularly higher than other major plastics. For example, it was 37-39 yen $/ \mathrm{kg}$ for PE, 25-49 yen/kg for PP, 47-99 yen/kg for PS. Those which were purchased for recycling were priced at $17.8 \mathrm{yen} / \mathrm{kg}$ on average, ranging 4-22 yen $/ \mathrm{kg}$. Flakes of rigid PVC for pipes were traded at $50-70$ yen $/ \mathrm{kg}$ depending on the quality

43. PVC News, vol 34, 2000/9, JPEC http://www.pvc.or.jp/news/ 34-05.html. Accessed 14 Feb 2015

44. PVC News Vol. 71, 2009/12, JPEC http://www.pvc.or.jp/news/ 71-5.html. Accessed 14 Feb 2015

45. PVC News, vol 66, 2008/9, JPEC http://www.pvc.or.jp/news/ 66-4.html. Accessed 14 Feb 2015

46. PVC News, vol 75, 2010/12, JPEC, http://www.pvc.or.jp/news/ 75-4.html. Accessed 14 Feb 2015

47. "Law Concerning the Promotion of Procurement of Eco-Friendly Goods and Services by the State and Other Entities, 2000", http:// www.env.go.jp/en/laws/policy/green/index.html. Accessed 14 Feb 2015 